\title{
Active Participation in Online Communities among Varsity Students
}

\author{
Robert J. Nathan, Wan Syahirah, Khong Sin Tan, Seethaletchumy Thambiah, and Kim Piew Lai \\ Multimedia University, Melaka, Malaysia
}

\begin{abstract}
This study analyzes the crucial factors affecting university students' participation in online communities. The study examines the effect of the desire to: (i) connect with each other, (ii) earn money, and (iii) share files, as possible leads in university student's participation in online community. Statistical analyses were carried out on responses to questionnaires to determine the significant contributor. Data were collected through online and offline means. Five hundred samples were selected upon filtration for data analysis. Results reveal connecting with each other as the most important factor. To facilitate the adoption of university students to online Communities, several factors that community managers can focus on: (a) notifier midget embedded in internet messaging system, (b) points given for participating in online forums, (c) flexibility in the online design and (d) ease of online registration.
\end{abstract}

Keywords: Online Community, Community Managers, Online Participation, Varsity Students

\section{Introduction}

Most students if not all are now members of online community. There are many to choose from which includes MySpace, Friendster, Facebook, Twitter and etc. It has somewhat became a necessity for every student to have at least one account in one of these online community sites. The explosive growth of online communities' sites has captivated university students to use this medium as a means of gathering information, establish and maintain social networks through these online community sites. To set up a profile is very easy and does not require any fee. Users just need to fill in a simple online form and submit it Online. The simplicity of joining such networks has successfully attracted millions of students worldwide into joining these online social networks.

Once a visitor becomes a member, he or she will be directed to a "profile page". The "profile page" allows the users to write their biography and customize their webpage with the help of several easy-to-use applications that are readily available. Users are always encouraged to share their "profile page" with other members in the network. Usually one expands his or her network by inviting friends through email to join and view their "profile page". This basically works just like viral marketing. For example, student A creates a profile in Facebook; after completing the profile, student A gets the option to invite friends to view his or her page. If student $\mathrm{A}$ invites 10 friends, these 10 friends can choose to register and become members of this online community and in turn invite 10 or more friends. This process repeats and spreads throughout the Internet with many people receiving invitations to join such networks. This explains the explosion of online communities in the cyberspace. It is also capturing the attention and commitment of varsity students to participate and eventually be actively committed in their communities.

\subsection{Research Background}

Varsity time and experience is often attributed by many as their most significant moments of their lives. Students usually enter varsity at the age of 18 to 21 years old and remain until they are 22 up to 26 years old depending on the programs they undertake.

Spending time in the varsity, being far from home, family and childhood friends, students are on the lookout to try new relationships with the hope to build meaningful and lasting Copyright (C) 2011 Robert J. Nathan, Wan Syahirah, Khong Sin Tan, Seethaletchumy Thambiah, and Kim Piew Lai. This is an open access article distributed under the Creative Commons Attribution License unported 3.0, which permits unrestricted use, distribution, and reproduction in any medium, provided that original work is properly cited. The article is a reprint from a 2009 article. Contact author: Robert J. Nathan. E-mail: robert.jeyakumar@mmu.edu.my 
friendships. Very often they are successful. Most people tend to make lifelong friends during their varsity days.

Various avenues are attractive to students when it comes to making new friends. Besides the conventional ways of meetings friends in class or hallways, the Internet has now paved the way to meet with people in the cyberspace. Without geographical boundaries, the Internet offers the unlimited source of finding new friends with a few "mouse-clicks".

Upon becoming an active member of the online community, most varsity students would spend considerably large amount of time in building and maintaining their social network. Few factors are found to encourage them to remain active in such networks, which includes money. Members can post up details about what they want to sell to their communities and gain access to worldwide market without spending much on advertisement. For example, a student can sell her guitar by displaying the details on her profile, and waits for interested buyers to approach her. Buyers can have the convenience to ask questions using Online Personal Messaging which is cheaper than calling. This activity will create ongoing communication between buyer and seller which prompts frequent logging to online communities.

Online communities also offer a cost-effective and fun way of connecting people. Personal "profile page" allows members to put their personal details such as pictures, biodata, journals (online blog link), interest and etc. Due to the dynamic nature of "profile page", which is constantly updated by users, people within the social networks tend to spend more time in online communities to view their friends' profile and to keep them updated with what's happening in their friends' (networks) lives.

File sharing or information sharing is yet another interesting feature of the online communities. Some online communities provide their users with the possibility to upload files in various formats such as mp3s, videos, movies, movie series, etc. This option enables users within a network to download files without any hassle and share them even with friends from other networks.

\section{Research Objectives and Hypothesis}

Participation and commitment to online communities are apparent among varsity students. This study seeks to empirically measure the factors that are associated with the strong participation of varsity students towards online communities.

Each social network has a different emphasis on its community and style. The common aspect or feature is the ability to connect people and enable communication among members (Notess, 2008). Online communities offer each member their own customizable page which is known as "profile page". The "profile page" has more than just user-details, which includes possibility for self-expression and enable more ways to play asynchronously. For example, all social networking sites enable you to show off your "friends" and leave public comments for them (Moore, 2008).

Facebook for example allows their users to state their current activity in a space called "what are you doing now?" Members can state their current activity; their mood and feelings etc in this space to let others in their network know their current condition. Many users find it a pleasure to constantly update this space to keep others informed. With people updating their information and viewing others' information constantly, the social network grows with userparticipation. Most users are oblivious to the fact that they are already committed to constantly update their status and be informed on others' status in their social networks.

Hypothesis 1: The opportunity for university students to connect with each other causes them to actively participate in online communities.

Making the extra cash is often at the back of every student's mind. Online communities offer such possibilities for students to generate money. The online communities allow users to sell things online. The transaction process is simple and easy where everything is done online with a minimal fee or free for selling online. Members can post up details about the thing they want to sell on the online communities and gain access to worldwide market without spending much on advertisement. The opportunity to make money through the online communities is hence believed to motivate students to participate in online communities.

Hypothesis 2: The opportunity for varsity students to earn money through online communities causes them to actively participate in online communities. 
Online communities also serve as a huge hub of information and knowledge sharing. Various types of information can be stored and shared online, including movies, songs, mp3s, applications and many more. The online groups exhibit a wide range of characteristics and serve a variety of purposes. It allows for small groups to engage in tightly focused discussions of specific topics, as well as big groups with hundreds of simultaneous participants, who are linked by similar interest or goals (Wilson and Peterson, 2002). The growth of file sharing technology and Internet allows people to utilize them in sharing and exchanging information Online.

Hypothesis 3: The ability for university students to share files through online communities causes them to actively participate in online communities.
This study believes that the variables identified above are related to each other in a cycle fashion, one leading to the other, as depicted in Figure 1. The online communities that provide various applications and platforms to upload and share information attract varsity students to use these platforms for file / information sharing. As more information are uploaded in the community, more people find it attractive to join and participate in such communities as they can get access to the information they want at the same time be connected to their circle of friends. With more and more people joining the network, the possibility to make money through the network grows as well. More people simply mean bigger market for buying and selling. The commerce aspects of online communities continue to keep their users committed to the network. With more people converting the online communities to an electronic commerce facility, more information is shared through the community. This cycle continues.

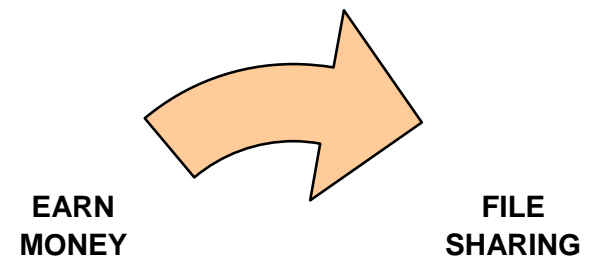

ACTIVE

PARTICIPATION

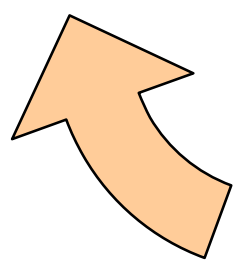

CONNECT

PEOPLE

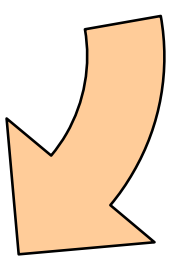

Figure 1. Cycle that leads to active participation in online communities

\section{Research Methodology}

The study seeks to test the hypotheses presented above based on the research framework as below (Figure 2): 


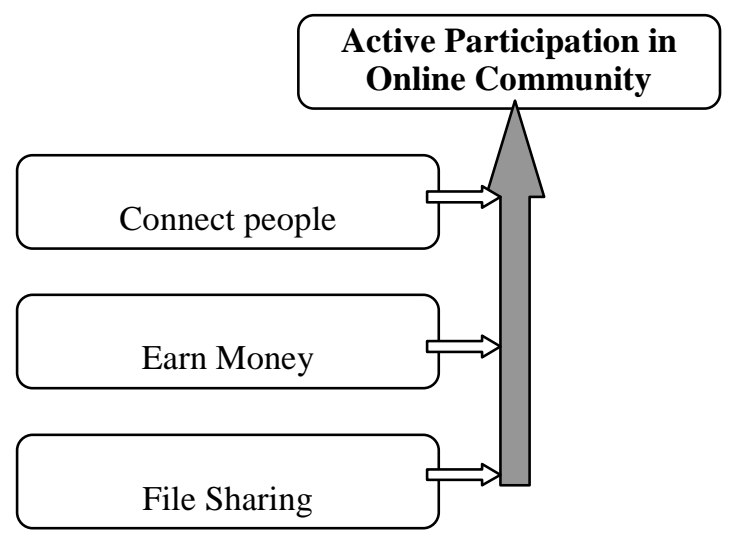

Figure 2. Research Framework

This framework depicts that connecting people, earning money and sharing of files through online communities are factors associated with the active participation of varsity students in online communities.

\subsection{Research Instrument and Sampling}

A set of questionnaire consisting 27 questions was used as the research instrument to collect the needed research data. The questionnaire is divided into 4 parts; $1^{\text {st }}$ part is gathers demographic information of respondents; $2^{\text {nd }}$ to $4^{\text {th }}$ part measures the independent and dependent variables of the study.

The first section seeks information of respondents such as gender and age preceded by a screening question which qualifies respondents for the study, i.e. respondents must be a varsity student at the time of responding to the questionnaire. The first section also contains questions that measure the active online community participation of respondents to the online communities.

For section 2, 3 and 4, the questionnaire contains skip questions; open-ended and closed ended multiple answer questions. The questions were tailored to investigate and collect underlying motives of respondents with regards to online community participation and the three independent variables of the study; connecting people, earning money and sharing files.

Questionnaires were distributed through online and print media. Printed questionnaires were circulated among varsity students in higher learning institutions in Malaysia, comprising northern, central and southern region. Online questionnaires were created and distributed via Survey Monkey (http://www.surveymonkey.com). Mixtures of both purposive and non-purposive sampling are present in the data collection. Hardcopies of questionnaires were distributed using convenient sampling while online questionnaires were sent out randomly to friends and colleagues in the mailing list. In addition, link to the online questionnaire was also posted in various weblogs that have high Page Ranking (received high traffic) and posting of the link through instant messaging services such as Yahoo! Messenger and MSN Messenger.

\section{Result and Discussion}

As this is an ongoing study, over 500 respondents who have currently participated in the survey were selected for data analysis; this includes online and offline data. The data were transcribed and coded into Statistical Package for Social Sciences (SPSS) software, version 15.0. Upon screening for consistency and filtering the data, 470 samples were finalized for data analysis in this preliminary analysis. This section presents the results of data analysis followed by discussions of the findings. Out of 470 respondents who participated in the research, 215 (45.7\%) were Male and 255 $(54.3 \%)$ were Female respondents. Although the two genders are not equally represented, there is no large difference in their numbers; both are within $\pm 5 \%$ from $50 \%$. Further analysis was carried out to investigate a possible gender effect towards online community active participation. 
Table 1: Cross-tabulation of Gender and Active Participation

\begin{tabular}{ccccc} 
& & \multicolumn{2}{c}{ Active } & Total \\
\cline { 3 - 4 } & & Yes & No & \\
\hline Gender & Male & 95 & 120 & 215 \\
& & $44.4 \%$ & $46.9 \%$ & $45.7 \%$ \\
\cline { 2 - 4 } & Femal & 119 & 136 & 255 \\
& $\mathbf{e}$ & $55.6 \%$ & $53.1 \%$ & $54.3 \%$ \\
\hline \multirow{2}{*}{ Total } & 214 & 256 & 470 \\
& & $100.0 \%$ & $100.0 \%$ & $100.0 \%$ \\
\hline
\end{tabular}

The cross-tabulation table above (Table 1) shows that there are a higher percentage of female varsity students who are active in online communities compared to male students. However a Chi-Square analysis between gender and active participation revealed a Chi-Statistics value of 0.289 and a p-value of 0.591 ( $>0.05$ significance level). Hence, there seems to be no statistical difference between male and female with regards to their online community participation.

Table 2: Cross-tabulation of Age Group and Active Participation

\begin{tabular}{llllll} 
& & \multicolumn{2}{c}{ Active } & Total \\
\cline { 2 - 5 } & & Yes & No & \% Yes / Total & \\
\hline Age & $\mathbf{1 8 - 2 0}$ & 91 & 118 & $91 / 209$ & 209 \\
& & $42.5 \%$ & $46.1 \%$ & $43.5 \%$ & $44.5 \%$ \\
\cline { 2 - 5 } & $\mathbf{2 1 - 2 3}$ & 113 & 123 & $113 / 236$ & 236 \\
& & $52.8 \%$ & $48.0 \%$ & $47.9 \%$ & $50.2 \%$ \\
\cline { 2 - 5 } & $\mathbf{2 4 - 2 6}$ & 6 & 7 & $6 / 13$ & 13 \\
& $2.8 \%$ & $2.7 \%$ & $46.1 \%$ & $2.8 \%$ \\
\cline { 2 - 5 } & $\mathbf{2 7}>$ & 4 & 8 & $4 / 12$ & 12 \\
& $1.9 \%$ & $3.1 \%$ & $33.3 \%$ & $2.6 \%$ \\
\hline Total & 214 & 256 & & 470 \\
& $100.0 \%$ & $100.0 \%$ & & $100.0 \%$ \\
\hline
\end{tabular}

The age group of respondents participated in the study are mostly between 21 to 23 years old $(50.2 \%)$ followed by 18 to 20 years old (44.5\%). The percentage of students with active participation in online communities seem to be higher in the lower age groups and seems to have declined in the age group 27 years old and above (Table 2).
A Chi-Square analysis between age group and participation shows a result of Chi-Statistics 1.581 and $p$-value $0.664 \quad>0.05$ significance level). There is no statistical difference between the age group and active participation in the online communities.

Hypothesis 1: The opportunity for university students to connect with each other causes them to actively participate in online communities. 
Table 3: Cross-Tabulation of Connecting People and Active Participation

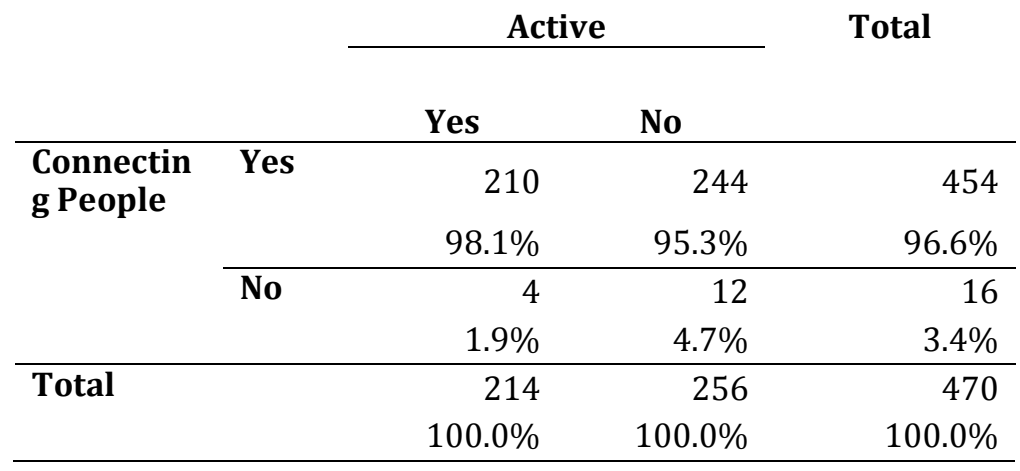

The Chi-Statistics for the test above (Table 3) is 2.816 with $\mathrm{p}$-value of 0.093 (significant at 0.1 significance level). There seems to be a significant association between varsity students' intention of using online communities for connecting people and their active participation in the online communities.
Hence $\mathrm{H} 1$ is substantiated.

Hypothesis 2: The opportunity for varsity students to earn money through online communities causes them to actively participate in online communities.

Table 4: Cross-Tabulation of Making Money and Active Participation

\begin{tabular}{lrrrr} 
& & \multicolumn{2}{c}{ Active } & \multicolumn{1}{c}{ Total } \\
\cline { 2 - 4 } Making & Yes & 78 & 87 & 165 \\
& & $36.4 \%$ & $34.0 \%$ & $35.1 \%$ \\
\cline { 2 - 5 } & & 136 & 169 & 305 \\
& No & $63.6 \%$ & $66.0 \%$ & $64.9 \%$ \\
\hline Total & & 214 & 256 & 470 \\
& & $100.0 \%$ & $100.0 \%$ & $100.0 \%$ \\
\hline
\end{tabular}

The Chi-Statistics for the test above (Table 4) is 0.311 with $p$-value of 0.577 ( $>0.05$ significance level). Although there are about $35 \%$ of varsity students who use online communities as a means to earn extra income, there seems to be No significant statistical association between their intention of using online communities for earning money and their active participation in the online communities.
Hence $\mathrm{H} 2$ is not substantiated.

Hypothesis 3: The ability for university students to share files through online communities causes them to actively participate in online communities.

Table 5: Cross-Tabulation of Sharing Files and Active Participation

\begin{tabular}{lrrrr} 
& & \multicolumn{2}{c}{ Active } & \multicolumn{1}{l}{ Total } \\
\cline { 3 - 4 } & & \multicolumn{1}{c}{ Yes } & \multicolumn{1}{c}{ No } & \\
\hline Sharing & Yes & 187 & 223 & 410 \\
& & $87.4 \%$ & $87.1 \%$ & $87.2 \%$ \\
\cline { 2 - 5 } & No & 27 & 33 & 60 \\
& & $12.6 \%$ & $12.9 \%$ & $12.8 \%$ \\
\hline Total & & 214 & 256 & 470 \\
& & $100.0 \%$ & $100.0 \%$ & $100.0 \%$ \\
\hline
\end{tabular}


The Chi-Statistics for the test above (Table 5) is 0.008 with $p$-value of 0.929 (>0.05 significance level). There is a huge majority of $87.2 \%$ of varsity students who use the online communities as a means for sharing files; however there seems to be No significant statistical association between their intention of using online communities for sharing files and their active participation in the online communities.

Hence $\mathrm{H} 3$ is not substantiated.

\section{Conclusion and Recommendation}

From the study, only one variable was found to play a significant role on active participation of university students towards online communities which is "connect with each other". Online businesses, especially online communities should focus more on providing web tools that enhances abilities to connect with others easily. Website developers can increase the opportunities to attract more people through their current members by providing the ability to invite their friends to join the online communities. Enabling users to know each others shared interests, experiences, values, or world views are positively welcome by online communities users to attract them further to participate closely in the community.

Feeling that warm and fuzzy moment of true connection with another person also helps to popularize the online communities. Connection wizards help users to get along with people, have good conversations, helps users to understand each other better, assist users in forming relationships, and make interacting more rewarding (Succeed Socially, 2009). For instance, online communities can provide option to users to invite friends' through individual email addresses or import their online address book to invite everyone to the community, known as the online address book (Address Book, 2009).

Online product developers can develop 'notifier widget' i.e. mini applications that reside in the computer (W3C, 2008). The Online Communities Notifier is an application that alerts users when they have new messages or updates in the online communities through the user's system tray in an unobtrusive manner. Such user-friendly technologies are widely accepted by online communities' users (Tschabitscher, 2008).

Point systems are also an effective way of taking something with no tangible value and turning it into an attractive virtual currency (Stamatiou, 2008a). This allows users to be recognized by the community. Usually, point based system is seen in forums, where they will gain points as they reply to threads. The users with the most total points will be popular in the forum as their username will be displayed in the front page of online communities. Sometime, with certain amount of points, the status of the user is change from 'Normal User' to 'Expert User' (Bruckman, 2006). It helps to spur users to contribute and act within the community. It creates motivation that comes from each user's desire to maintain a reputation as well as earn respect from audience (Resnick, Bruckman \& Martin, 2006).

Online communities' managers could also allow for flexibility in the online communities design and allow more freedom in the usage of the online communities among users (Kembel, 2008; 2009). For example, previously Friendster does not offer its users much option in modifying their profile such as creating a decorative background etc., Facebook overcame this limitation by offering various free programs that allows flexibility and was able to attract a wider audience.

Users in a social community may feel reluctant to actively participate in a social community and interact with other users who do not have profile information such as name, pictures etc. (Stamatiou, 2008b). It helps users participating in online communities to interact and establish a sense of connection with others if they have more information about them. Online communities' managers can solve this by simplifying the account creation during registration would encourage new users to share information fast, and eventually reduce the amount of anonymous users in the community. This effort in the long run is believed to increase the connection among user (Stamatiou, 2007a).

It is a good idea for online communities' managers to put up a community content suggestion and voting application. It is a usergenerated content suggestion application for online communities that effortlessly assemble what users really want to have in their online 
communities (Stamatiou, 2007b). By adding the tool to online communities, users have the ability to post suggestions about what they want to see in the online communities while online communities' managers will know what to specifically improve on their community website.

In conclusion, university students actively participate in online communities because of the sense of belonging afforded by the communities. Community managers can facilitate this through simplifying the registration process, allowing more room for flexibility in the online profile page design, provide acknowledgement of responses through online reward system (points systems) and provide unobtrusive and subtle notification on incoming messages.

\section{Limitation and Future Study}

In this preliminary finding, only three variables related to the active online participation of varsity students are analysed and discussed. The sampling method employed is purposive sampling which may not accurately represent the population adequately; however due to the nature of the study which is cyberspace oriented, online convenience sampling was selected as the appropriate sampling procedure. The data that is collected in this study is mostly nominal scaled, hence limiting the statistical analysis options to only non-parametric analysis. These weaknesses can be addressed in future studies.

Future study could incorporate more variables that could be significant in affecting students' participation and eventually lead to their active participation in online communities. Issues such as website usability (Nathan, Yeow \& Murugesan, 2008; Nathan \& Yeow, 2009) or website security (Tan, Chong, Lin \& Eze, 2009) can also be investigated in relation to their effect to student participation to online communities.

\section{References}

Address book (2009) Available: http://en.wikipedia.org/wiki/Address_Book

Bruckman, A. (2006). Cyberspace is Not Disneyland:

The Role of the Artist in a Networked World. Journal of Interactions, Vol. 3, pp. 67.

Kembel, J. (2008) Community + Innovation: Agile Commons. Available: http://community.hivelive.com/posts/2b41ee9 d73
Kembel, J. (2009) Community requires multiple points of view. Available:

http://community.hivelive.com/posts/a16214c $9 \mathrm{e} 8$

Moore, B (2008) On the Convergence of Virtual Worlds and Social Networking Sites. Available: http://terranova.blogs.com/terra_nova/2008/0 2/on-the-converge.html

Nathan, R.J, Yeow, P.H.P and Murugesan, S. (2008) "Key usability factors of service-oriented web sites for students: an empirical study", Online Information Review, Vol. 32 No.3, pp.302324.

Nathan, R.J \& Yeow, P.H.P (2009) "An Empirical Study of Factors Affecting the Perceived Usability of Websites for Student Internet Users", Universal Access in the Information Society, Vol. 8 No. 3, pp. 165.

Notess, G.R. (2008) An About-Face on Facebook? Available:

http://www.allbusiness.com/technology/softw are-services-applications-internet/105901391.html

Resnick, M., Bruckman, A. \& Martin, F. (2006)

Pianos Not Stereos:

Creating Computational Construction Kits. Journal of Interactions, Vol. 3, pp. 6.

Stamatiou, P. (2007a) Online Presence and Why You Need It (2007) Available: http://paulstamatiou.com/2007/04/14/onlinepresence-and-why-you-need-it

Stamatiou, P. (2007b) What is Skribit? Available: http://paulstamatiou.com/2007/11/23/whatis-skribit

Stamatiou, P. (2008a) Community Design: Points as Motivation. Available:

http://paulstamatiou.com/2008/04/17/commu nity-design-points-as-motivation

Stamatiou, P. (2008b) The Perils of the Anonymous User. Available: http://paulstamatiou.com/2008/03/25/theperils-of-the-anonymous-user

Succeed Socially (2009) Thoughts on 'Connecting' With People. Available: http://www.succeedsocially.com/connect

Tan, K. S., Chong S. C., Lin, B. and Eze, U. C. (2009b). "Internet-Based ICT Adoption: Evidence from Malaysian SMEs”, Industrial 
9 Journal of Internet Social Networking and Virtual Communities

Management \& Data Systems, 109(2), pp. 224-

244.

Tschabitscher, H (2008) Gmail Notifier 1.0.25.0 -

Gmail Mail Checker. Available:

http://email.about.com/od/gmail/gr/gmail_not ifier.htm

W3C (2008) Widgets 1.0: Working Draft.

Available:

http://www.w3.org/TR/widgets-updates/

Wilson, S.M. and Peterson, L.C. (2002). The

Anthropology of Online Communities. Annual.

Review of Anthropology, Vol. 31(1), pp 44 